\title{
EXPLORATORY AND CONFIRMATORY FACTOR ANALYSIS OF PERCEIVED SELF-EFFICACIES AMONG TEACHERS STUDENTS AT FACULTY OF EDUCATION, HELWAN UNIVERSITY, EGYPT: FROM BANDURA'S THEORY TO PROPOSED MODEL
}

\author{
Dina Samir Sayed Ali Mekkyi, \\ Mohamed Atef Mohamed Mohamed El- Badramany \\ Lecturer of Educational Psychology, \\ Faculty of Education, Helwan University, \\ Egypt
}

\begin{abstract}
:
The purpose of this study is to examine the validity and reliability of perceived selfefficacies questionnaire (PSE) which is designed for university students at faculty of education. A total of 472 students participated, selected by using cluster random sampling. In order to examine the construct validity of the PSE, Quantitative data were analysed using exploratory factor analysis (EFA) and confirmatory factor analysis (CFA) using SPSS 23 and AMOS 23. EFA revealed similar structures from prior research and the present study. The CFA approach verified the questionnaire of perceived self-efficacies was satisfactory for university students' context. This work concludes the perceived selfefficacies of university students have a nine-factor structure: Planning perceived selfefficacy, Moral and emotional perceived self-efficacy, Social leadership perceived selfefficacy, Academic perceived self-efficacy, Reading perceived self-efficacy, Technology perceived self-efficacy, Research perceived self-efficacy, Motivated perceived selfefficacy and Creative perceived self-efficacy. The goodness of fit indices values shows good fit for self-efficacies with nine factors. According to these findings, the PSE is appropriate for researchers or teaching staff whose aim is to measure his/her students perceived self-efficacies beliefs.
\end{abstract}

Keywords: perceived self-efficacies, exploratory factor analysis, confirmatory factor analysis

\section{Introduction}

Perceived efficacy is a psychosocial construct put forth by Albert Bandura, and Bandura is among the most famous cognitive psychologists of the twentieth century. By virtue of

i Correspondence: email dinamekky@yahoo.com 
Dina Samir Sayed Ali Mekky, Mohamed Atef Mohamed Mohamed El- Badramany

EXPLORATORY AND CONFIRMATORY FACTOR ANALYSIS OF PERCEIVED

SELF-EFFICACIES AMONG TEACHERS STUDENTS AT FACULTY OF EDUCATION,

HELWAN UNIVERSITY, EGYPT: FROM BANDURA'S THEORY TO PROPOSED MODEL

his clinical work, he always works to help individuals overcome their anxiety and fear of things like snakes. Bandura proposed the Social Cognitive Theory (SCT) to help him predict and explain the psychological changes achieved by the various therapeutic methods he used, and in this theory, Bandura believed that individuals are capable. On making things happen on purpose through their actions, and that things always happen when individuals believe in their abilities to do them (perceived efficacy) (Short, 2014).

It is worth noting that the concept of perceived efficacy is one of the important concepts in the interpretation of human behavior, especially from the point of view of social learning theorists. Researchers in the Arab environment have dealt with the term self-efficacy, and it translated into self-efficacy, self-efficacy, self-efficacy, or perceived efficacy. The concept of perceived efficacy appeared at the hands of the American scientist Bandura (1977) when he presented an integrated theory for this concept in which he identified the dimensions and sources of perceived efficacy. This theory represents an important aspect of the theory of social learning, and it is the main determinant of individual behavior.

Bandura (1997) defined perceived efficacy as the individual's beliefs about his ability to organize and implement plans, the courses of action required to achieve certain types of performance, and the achievement of goals desired to be achieved, it expresses the individual's confidence in his ability to organize and employ the necessary cognitive and behavioral social skills. To perform successfully in a task, and it is considered part of the theoretical framework called social cognitive theory, which assumes that human activities and performances depend on three factors, namely: the behavior of the individual, personal factors, and environmental conditions, and these factors interact with each other and have a mutual influence. Among them, Pandora called it reciprocal determinism.

Bandura (1995) has further emphasized that beliefs of perceived efficacy determine how people feel, think, motivate themselves and act, and provide the basis for human motivation, well-being, and personal achievement; this is because as long as individuals do not realize that their actions and behaviors can lead to the results they deserve, they will have little incentive to act or persevere in the face of difficulties. The foregoing supports what Margolis \& McCabe (2006) pointed out that the low level of perceived efficacy leads to problems with motivation in students. If students think that they cannot succeed in specific tasks (perceived decrease in efficacy), then they will try to accomplish these tasks superficially, or they quickly surrender, avoid or resist it.

And perceived academic efficacy is highly related to student learning, cognitive integration, analytical thinking, academic commitment, perseverance, susceptibility to positive emotions, negative emotions, and achievement (Linnenbrink \& Pintrich, 2003). There are statistically significant relationships between perceived academic efficacy, planning, control, and organization. They also have a direct and statistically significant impact on metacognitive learning strategies (Hayat \& Shateri, 2019). 
Dina Samir Sayed Ali Mekky, Mohamed Atef Mohamed Mohamed El- Badramany

EXPLORATORY AND CONFIRMATORY FACTOR ANALYSIS OF PERCEIVED

SELF-EFFICACIES AMONG TEACHERS STUDENTS AT FACULTY OF EDUCATION, HELWAN UNIVERSITY, EGYPT: FROM BANDURA'S THEORY TO PROPOSED MODEL

Consistent with the above, perceived academic aptitude helps students to perform and complete tasks well; students with good perceived efficacy tend to be proactive, competitive and creative, and in doing so, perceived academic efficacy improves learning outcomes (Laurencelle \& Scanlan, 2018) and has a positive effect on students; they make it easier for students to make decisions and raise their level of self-confidence (Penn \& Lent, 2019), while students with low perceived efficacy tend to avoid challenging tasks (Toharudin, Rahmat \& Kurniawan, 2019).

Educators can undertake these activities to enhance and develop the perceived efficacy of learners by: planning medium-difficulty tasks, using peer modeling, teaching them specific learning strategies, leveraging students' choices and interests in their learning, enhancing effort and using correction strategy (Margolis \& McCabe, 2006).

Perceived efficacy also plays an important role in participation, academic inclusion and achievement. So, it is imperative for teachers to collect their own experiences. In order to employ it in the development of perceived efficacy in their students by: helping students maintain beliefs of perceived efficacy relatively high and accurate, and providing students with relatively difficult academic assignments that most students can access, fostering the belief that efficacy is a changeable and controllable aspect, and its development, reinforcing students' domain-specific perceived efficacy beliefs rather than general self-esteem; whereas, despite the importance of general selfesteem, it is more important for students to learn to have accurate observations about their performance (Çubukcu, 2008).

In addition to the above, the perceived efficacy of pre-service teachers may be developed through teacher preparation that includes training (practical education) with basic and experienced teachers where pre-service teachers can observe them while explaining to students, how to apply teaching skills in practice, and in the end the teacher moves pre-service to the stage of self-practice, and actual teaching skills. As for in-service teachers, continuing professional development can help them learn new strategies to use in difficult situations, such as how to enhance learning in students with different abilities, and how to work with students with limited efficacy (Schunk, 2012).

The Sources of perceived efficacy are determined in light of past performance achievements (also called mastery or performance experiences or experiences of mastery or mutual mastery experience), alternative experiences (also called social comparisons, observational learning, or modeling), verbal persuasion (defined as methods of persuasion and encouragement, which they provide). A group of socially influential people, including coaches, colleagues, parents, teachers, and even the person himself), physiological state (such as heartbeat, respiratory rate) and emotional (such as mood, emotions and emotions) (Short, 2014; Bandura, 1997).

A group of socially influential people, including coaches, colleagues, parents, teachers, and even the person himself), physiological state (such as heartbeat, respiratory rate) and emotional (such as mood, emotions and emotions) (Short, 2014). The present research further analysed the factors of perceived self-efficacies among university 
students using the Exploratory Factor Analysis, after getting the result and most significant factors, it was extracted in the Confirmatory Factory Analysis.

Perceived self-efficacy, related to different domains of functioning in which human experience occurs, contributes towards building the psychological effectiveness and psychosocial adjustment-styles of individuals in relation to their particular environments. a group of influential persons socially, including trainers, colleagues, and parents, teachers and even the same person), and the status of physiological (such as heartbeat, breathing) and emotional rate (such as mood, emotions and emotions).

The construct of perceived self-efficacy is the belief that one can perform novel or difficult tasks and attain desired outcomes, as spelled out in the Social Cognitive Theory (Bandura, 1997). This "can do"-cognition reflects a sense of control over one's environment and an optimistic belief of being able to alter challenging environmental demands by means of one's own behavior. Hence, it represents a self-confident view of one's capability to deal with certain stressors in life.

Several studies confirm that perceived efficacy is not only associated with high levels of achievement, but also with many adaptive academic outcomes. Linnenbrink \& Pintrinch (2002) indicated that there is a positive correlation between the perceived efficacy of the student and his use of cognitive organization strategies. Some studies and research have also found conducted on university students, including (Al-Zaq, 2009) that the level of perceived efficacy increases with the increase in academic level. The results of some studies and research related to the extent of the difference in perceived efficacy according to the gender variable have differed. Al-Mikhlafi (2010) confirmed that the perceived efficacy of females is higher than that of males, while the study of Hamdi and Daoud (2000) indicated that the perceived efficacy of males is higher. Of perceived efficacy in females. The results of Al-Zaq (2009) study showed that the relationship between perceived efficacy and gender was not statistically significant. As for the results of studies on academic specialization, the study of Muhammad Al-Rufou, Al-Qaisi, and Al-Qaraah (2009) indicated that students of the College of Science were higher in the level of perceived efficacy than the rest of the other colleges.

In this field, there are many studies and research that dealt with perceived efficacy in general, and perceived academic efficacy in particular in relation to some variables, including, but not limited to: emotional intelligence (Chan, 2004; Adeyemo, 2007; Hashemi \& Ghanizadeh, 2011), and Job satisfaction, academic achievement and recognition of the role represented by cultural context and gender (Merolla, 2017; Aurah, 2017; Caprara, Barbaranelli, Steca, \& Malone, 2006), and some of them aimed to verify the impact of cross-cultural training on perceived efficacy and cultural intelligence, and to explore the relationship between them (Rehg, Gundlach \& Grigorian, 2012), and others dealt with perceived academic efficacy as a mediating variable in the relationship between the perceived academic climate and academic performance (Abd -Elmotaleb \& Saha, 2013). 
Also, some of them aimed to study the perceived academic efficacy in light of the social demographic variables of university students (Satici \& Can, 2016), and some of them concluded that cognitive alternatives increase the perceived efficiency and academic performance of students (Iyer, Zhang, Jetten, Hao \& Cui, 2017), and in the same context, Minter and Pritzker (2017) aimed to measure the perceived social and academic efficacy of adolescents, while Drago, Rheinheimer \& Detweiler (2018) also aimed to identify the impact of the control center, the perceived academic efficacy on academic performance, among which it aimed to study the effect of creativity, social context, and perceived efficacy on the intention of entrepreneurship (Bellò, Mattana \& Loi, 2018).

After the researchers familiarized themselves with many definitions of perceived efficacy, among them (Kim \& Park, 2000; Merriman, 2012; Shehzad, Lashari, Lashari\& Hasan, 2020), the procedurally perceived self-efficacies can be defined as: Student confidence in his ability to perform the desired activities and behaviors, his flexibility in dealing with difficult situations, and the extent of his perseverance to accomplish the tasks assigned to him to successfully achieve the desired academic goals, and to reach an outstanding level of academic performance and achievement. Perceived academic, and its sub-dimensions.

\section{Components of Perceived Self-Efficacies}

\subsection{Planning Perceived Self-Efficacy}

Planning perceived self-efficacy(PPSE) refers to the student's ability to manage the various tasks according to a specific schedule, to achieve his goals and to organize himself according to predetermined priorities (Reuter, Ziegelmann, Wiedemann, Geiser, Lippke, Schüz, \& Schwarzer, 2010).

\subsection{Moral and Emotional Perceived Self-Efficacy}

Moral perceived self-efficacy(MPSE) may be described as the beliefs of individuals that they can effectively handle what is needed to achieve moral success (Hannah \& Avolio, 2010). This research, based on the theory of behavioral plasticity, suggests that when moral effectiveness is strong, the negative relationship between coercive supervision and moral courage will be reduced (Afsar, Shahjehan, Afridi, Shah, Bin Saeed \& Hafeez, 2019).

Considering the fact that beliefs in self-efficacy have been tested in numerous scientific fields and research has shown that beliefs in self-efficacy are successful in most scientific fields, studies have concentrated on the effects of these beliefs on research and this has produced a new term called research self-efficacy (Tiyuri, Saberi, Miri, Shahrestanaki, Bayat \& Salehiniya, 2018).

\subsection{Social Leadership Perceived Self-Efficacy}

Social leadership perceived self-efficacy (SLPSE) is regarded as one of the most important variables that determines the individual, group and outcomes of the organizations' activities, as it plays a very important role, particularly under stress or demanding 
situation (Hoyt, 2005). Leadership self-efficacy can be referred to as a person's perception of his/her general ability to lead and several researches conducted in the past, have shown strong and positive association between leadership self-efficacy and several forms of human performance (Semadar, Robins \& Ferris, 2006; Anderson, Krajewski, Goffin \& Jackson, 2008; Galoj, 2016).

\subsection{Academic Perceived Self-Efficacy}

Academic perceived self-efficacy (APSE) refers to student beliefs that improve learning include the following: encourage students to set clear, specific, and challenging proximal goals; provide students with honest and explicit feedback; facilitate accurate calibration of self-efficacy; and use peer modelling (Artino, 2012).

\subsection{Reading Perceived Self-Efficacy}

Reading perceived self-efficacy (RPSE): beliefs denote to learner's appraisals about their reading capabilities, i.e., how confident they are about achieving a specific reading task. Reading self-efficacy beliefs are influenced by the level of performance being achieved in the similar tasks by the readers; this contains any accompanying, response and reassurance received from the teacher (Wigfield, Guthrie, Tonks, \& Perencevich, 2004; Lashari, Shehzad, Lashari \& Alghorbany, 2019).

\subsection{Technology Perceived Self-Efficacy}

Technology perceived self-efficacy (TPSE) is "the belief in one's ability to successfully perform a technologically sophisticated new task" (McDonald \& Siegall, 1992). TSE does not highlight specific technological tasks; instead, it is purposely vague. This is a specific application of the broader and more general construct of self-efficacy, which is defined as the belief in one's ability to engage in specific actions that result in desired outcomes (Bandura, 1997). Self-efficacy does not focus on the skills one has, but rather the judgments of what one can do with his or her skills. Traditionally, a distinguishing feature of self-efficacy is its domain-specificity. In other words, judgments are limited to certain types of performances as compared to an overall evaluation of his or her potential. Typically, these constructs refer to specific types of technology; for example, computer self-efficacy, or internet self-efficacy and information technology self-efficacy. In order to organize this literature, technology specific self-efficacies (e.g., computer and internet) that technology specific self-efficacies can be considered sub-dimensions under the larger construct of technological self-efficacy( Joo, Bong \& Choi, 2000).

Technological self-efficacy is characterized as students' perception of their capabilities to utilize technology-related tools and sites to conduct learning behaviors so as to achieve intended learning outcome (Keengwe, 2007). Researchers have verified a significant positive influence of technological self-efficacy on technology acceptance and utilization (Celik \& Yesilyurt, 2013). Researchers have also found that technological self- 
Dina Samir Sayed Ali Mekky, Mohamed Atef Mohamed Mohamed El- Badramany

EXPLORATORY AND CONFIRMATORY FACTOR ANALYSIS OF PERCEIVED

SELF-EFFICACIES AMONG TEACHERS STUDENTS AT FACULTY OF EDUCATION,

HELWAN UNIVERSITY, EGYPT: FROM BANDURA'S THEORY TO PROPOSED MODEL

efficacy significantly affects students' behavioral preferences to use technological tools and their perceptions of the usefulness of technology for learning (Mew \& Honey, 2010).

\subsection{Research Perceived Self-Efficacy}

Research perceived self-efficacy(RPSE), which plays a key role in predicting the study of a person. Students with low self-efficacy in research are not sure of their ability to conduct a study and do not believe that their attempt will lead to success and are often nervous, especially when they are tested, they feel a lack of competence (Lev, Kolassa \& Bakken, 2010; Garavand, Kareshki \& Ahanchian, 2014).

Instead, students with greater self-efficacy believe in their own self-efficacy. Competencies have the potential and are more capable of investigating successful in research activities (Bierer, Prayson \& Dannefer, 2015).

\subsection{Motivated Perceived Self-Efficacy}

Although self-efficacy and motivation are profoundly intertwined, they are two distinct structures as well. Self-efficacy is based on the confidence of a person in their own ability to succeed, while motivation is based on the willingness of the individual to achieve. Many with elevated self-efficacy are also highly motivated and vice versa, but this is not a foregone conclusion.

Nevertheless, it is true that when a person gains or retains self-efficacy through the experience of achievement, however slight, they typically get a boost in motivation to continue learning and development. In order to establish a sort of success loop, the partnership may also operate in the other direction; when a person is highly motivated to learn and excel, they are more likely to accomplish their objectives, giving them an experience that contributes to their overall self-efficacy (Voica, Singer \& Stan, 2020).

\subsection{Creative Perceived Self-Efficacy}

Creative perceived self-efficacy (CPSE)is defined as "the belief one has the ability to produce creative outcomes" (Tierney \& Farmer, 2002). How self-efficacy are believed to be related to creativity is the same for all three levels: Individuals are much more likely to engage in tasks if they assume they will accomplish something and regard themselves as potentially successful. The motivation for a behavior is high when one expects a positive outcome (Haase, Hoff, Hanel \& Innes-Ker, 2018).

\section{Research Method}

\subsection{Population, Sample, and Sampling Techniques}

The population in this research was all second and third-grade students at faculty of education Helwan university in Egypt. The samples in this study were to 472 students. Cluster random sampling was applied as a sampling technique. 
Dina Samir Sayed Ali Mekky, Mohamed Atef Mohamed Mohamed El- Badramany

EXPLORATORY AND CONFIRMATORY FACTOR ANALYSIS OF PERCEIVED

SELF-EFFICACIES AMONG TEACHERS STUDENTS AT FACULTY OF EDUCATION,

HELWAN UNIVERSITY, EGYPT: FROM BANDURA'S THEORY TO PROPOSED MODEL

\subsection{Data Collection Method}

Perceived self-efficacies in this research was measured by employing Perceived selfefficacies scale Prepared by/ researchers. The scale of the study was arranged by referring to the suggested components of Perceived self-efficacies. An example of items on the Perceived self-efficacies scale was attached in Table 1.

Table 1: The example of learning perceived self-efficacy variable item

\begin{tabular}{|c|c|c|c|c|c|}
\hline Items & Strongly agree & Agree & Neutral & Disagree & Strongly disagree \\
\hline \multicolumn{6}{|c|}{ Planning perceived self-efficacy variable item: } \\
\hline \multicolumn{6}{|c|}{ I anticipate the consequences or effects of the action or action. } \\
\hline \multicolumn{6}{|c|}{ I had time to implement the steps involved in the process } \\
\hline \multicolumn{6}{|c|}{ I arrange the steps of any action in a reasonable order or an orderly sequence. } \\
\hline \multicolumn{6}{|c|}{$\begin{array}{l}\text { I am aware of the constraints of time, space, materials, and capabilities when working on group or } \\
\text { individual projects. }\end{array}$} \\
\hline \multicolumn{6}{|c|}{ Moral and Emotional perceived self-efficacy variable item: } \\
\hline \multicolumn{6}{|c|}{ I hate being selfish } \\
\hline \multicolumn{6}{|c|}{ I self-criticize myself } \\
\hline \multicolumn{6}{|c|}{ I have the ability to control and self-control } \\
\hline \multicolumn{6}{|c|}{ I feel the feelings and needs of others } \\
\hline \multicolumn{6}{|c|}{ Social leadership perceived self-efficacy variable item: } \\
\hline \multicolumn{6}{|c|}{ have the ability to be organized. } \\
\hline \multicolumn{6}{|c|}{ I tend to be a leader when I interact with others } \\
\hline \multicolumn{6}{|c|}{ I participate in social services } \\
\hline \multicolumn{6}{|c|}{ I have an extraordinary ability to influence others } \\
\hline \multicolumn{6}{|c|}{ Academic perceived self-efficacy variable item: } \\
\hline \multicolumn{6}{|c|}{ I have the ability to be organized. } \\
\hline \multicolumn{6}{|c|}{ I tend to be a leader when I interact with others } \\
\hline \multicolumn{6}{|c|}{ I participate in social services } \\
\hline \multicolumn{6}{|c|}{ I have an extraordinary ability to influence others } \\
\hline \multicolumn{6}{|c|}{ Reading perceived self-efficacy variable item: } \\
\hline \multicolumn{6}{|c|}{ I persevere in reading difficult topics. } \\
\hline \multicolumn{6}{|c|}{ I have a great passion for extensive reading in private fields } \\
\hline \multicolumn{6}{|c|}{ Reading satisfies my desire for knowledge } \\
\hline \multicolumn{6}{|c|}{ Reading is one of my favorite hobbies } \\
\hline \multicolumn{6}{|c|}{ Technology perceived self-efficacy variable item: } \\
\hline \multicolumn{6}{|c|}{ I possess a wide range of technological skills. } \\
\hline I master & anced technology & better $t$ & ny peers. & & \\
\hline I help otl & with issues with $\mathrm{t}$ & lology. & & & \\
\hline I employ & dern technology $t$ & form im & int and use & tivities & \\
\hline Research & rceived self-efficac & riable ite & & & \\
\hline I am inte & ted in excavating a & earching & he origin $\mathrm{o}$ & & \\
\hline I am curi & in the cultural anc & ellectual & & & \\
\hline I enjoy th & ower of observatio & d alertne & what is $\mathrm{gc}$ & $\mathrm{n}$ around $\mathrm{n}$ & \\
\hline I have a $\xi$ & at capacity for atter & & & & \\
\hline Motivate & erceived self-effica & ariable it & & & \\
\hline I am inte & ed in excavating a & earching & he origin $\mathrm{o}$ & & \\
\hline I am curi & in the cultural anc & ellectual & & & \\
\hline
\end{tabular}


Dina Samir Sayed Ali Mekky, Mohamed Atef Mohamed Mohamed El- Badramany

EXPLORATORY AND CONFIRMATORY FACTOR ANALYSIS OF PERCEIVED

SELF-EFFICACIES AMONG TEACHERS STUDENTS AT FACULTY OF EDUCATION, HELWAN UNIVERSITY, EGYPT: FROM BANDURA'S THEORY TO PROPOSED MODEL

\begin{tabular}{|l|}
\hline \hline I enjoy the power of observation and alertness to what is going on around me \\
\hline I have a great capacity for attention \\
\hline Creative perceived self-efficacy variable item: \\
\hline I have the ability to think imaginatively \\
\hline I have the power to generate a large number of ideas or solutions to the problems that I encounter. \\
\hline I have the power to come up with unusual and unique responses or ideas \\
\hline I have the ability to come up with new and original ideas and solutions. \\
\hline
\end{tabular}

Moreover, the blueprint used as a reference in preparing the perceived self-efficacy scale was presented in Table 2 .

Table 2: Perceived self-efficacy scale blueprint

\begin{tabular}{|c|l|l|c|}
\hline No & \multicolumn{1}{|c|}{ Component } & \multicolumn{1}{|c|}{ Item numbers } & \multicolumn{1}{|c|}{} \\
\hline 1 & Planning perceived self-efficacy & $31-37-52-53-54-55-56-57-58-59-60-61-62-63-64-65$ & 16 \\
\hline 2 & Moral and Emotional perceived self- & $36-38-89-91-92-93-94-95-97-100-101-102-106-108$ & 14 \\
& efficacy & & \\
\hline 3 & Social leadership perceived self-efficacy & $\begin{array}{l}32-35-39-40-42-43-44-45-46-47-49-50-51-90-98-99- \\
104-105\end{array}$ & 18 \\
& & $1-2-3-4-5-6-7-8-9-10-11-12-15$ & 16 \\
\hline 4 & Academic perceived self-efficacy & $17-20-23$ & 11 \\
& & $66-67-68-69-70-71-72-73-74-76-77$ & 8 \\
\hline 5 & Reading perceived self-efficacy & $78-79-80-81-82-83-84-85$ & 11 \\
\hline 6 & Technology perceived self-efficacy & $24-88-107-109-110-111-112-113-114-115-116$ & 8 \\
\hline 7 & Research perceived self-efficacy & $14-25-26-27-28-29-30-33$ & 7 \\
\hline 8 & Motivated perceived self-efficacy & $16-17-18-19-21-87-103$ & \\
\hline 9 & Creative perceived self-efficacy & & \\
\hline
\end{tabular}

\subsection{Item Writing}

Items for the Perceived self-efficacies inventory (PSEI) were constructed based on the sources of Bandura's principal sources of self-efficacy. The items were classified according to Planning perceived self-efficacy, Moral and emotional perceived selfefficacy, Social leadership perceived self-efficacy, Academic perceived self-efficacy, Reading perceived self-efficacy, Technology perceived self-efficacy, Research perceived self-efficacy, Motivated perceived self-efficacy and Creative perceived self-efficacy. The scaling technique used was a five-point verbal frequency scale.

Each interval in the scale is coded with numerical value where $(5=$ strongly agree; $4=$ agree; 3 = neutral; $2=$ disagree and $1=$ strongly disagree). There were 118 items judged by experts as to whether it was accepted, needs revisions, or rejected. Out of 118 items a total of 109 items remained and used in the study. The items were arranged by its category and the respondents answered by encircling the number corresponding to their answer.

\subsection{Data Analysis}

The survey questionnaire tool for Perceived Self-efficacies was constructed and validated first using the Exploratory Factor Analysis (EFA). This procedure was meant to further 
Dina Samir Sayed Ali Mekky, Mohamed Atef Mohamed Mohamed El- Badramany

EXPLORATORY AND CONFIRMATORY FACTOR ANALYSIS OF PERCEIVED

SELF-EFFICACIES AMONG TEACHERS STUDENTS AT FACULTY OF EDUCATION,

HELWAN UNIVERSITY, EGYPT: FROM BANDURA'S THEORY TO PROPOSED MODEL

explore the factors on perceived self-efficacies among teachers student. The reliability of items in perceived Self-Efficacies Inventory (SEI) was determined using Cronbach's Alpha with an index of .76 which shows good reliability. After the EFA, factor structure was tested using the Confirmatory Factor Analysis (CFA). The CFA approach used was Structural Equations Modeling (SEM) with a maximum likelihood of the variance. Goodness of fit indices was used to test the model for both non-centrality interval estimation and single sample goodness fit indices. The univariate statistics such as mean, standard deviation, skewness and kurtosis were reported to determine the variability of the measures.

\section{Results and Discussion}

\subsection{Exploratory Factor Analysis}

The researchers conducted exploratory factor analysis using the statistical packages program in educational and psychological sciences (SPSS v.23) on a sample of (472) students and students at the Faculty of Education of Helwan University of different scientific disciplines, and was based on the test of Kaiser Kaisr Criteria, a statistical test proposed by Guttman (1954), and his idea is based on the acceptance of factors whose underlying root increases the right and are general factors.

Hottelling's Principle Component method (1933) has also been used as the most widespread method of worker analysis; Promax Rotation, Hendrickson and White(1964) was performed in which the axes were managed without keeping the perpendicularity between them, and the oblique factors between them were overlapping and linked.

Exploratory Factor Analysis was first used to explore the factor structure of perceived self-efficacies. The Principal Component Analysis procedure extracted nine factors (the highest eigenvalues were 41.48 and lowest eigenvalues were 1.87). Using the Promax raw rotation, out of 118 items, 109 were significant, considered acceptable items, and highly loaded in factor marked loading of .35. The total mean score of all 472 respondents along with the 109 items was $\mathrm{M}=408.29, \mathrm{SD}=49.55$, skewness $=-0.60$. The distribution is said to be left skewed, the tail is longer and it has a few low values and kurtosis $=0.91$. The consistency of the self-efficacy using Cronbach's alpha was high (.76) which explains the reliability of the items. As a result, a total of 109 items remained and the factors are labeled as: Planning perceived self-efficacy, Moral and emotional perceived self-efficacy, Social leadership perceived self-efficacy, Academic perceived self-efficacy, Reading perceived self-efficacy, Technology perceived self-efficacy, Research perceived self-efficacy, Motivated perceived self-efficacy and Creative perceived self-efficacy.

Table 3 shows the accepted items with their factor loadings to each factor. In the present study, all suggested 109 items for measuring perceived self-efficacies were registered by high loading factors ranging from 0.309 to $0.902(>0.50)$. 
Dina Samir Sayed Ali Mekky, Mohamed Atef Mohamed Mohamed El- Badramany

EXPLORATORY AND CONFIRMATORY FACTOR ANALYSIS OF PERCEIVED

SELF-EFFICACIES AMONG TEACHERS STUDENTS AT FACULTY OF EDUCATION,

HELWAN UNIVERSITY, EGYPT: FROM BANDURA'S THEORY TO PROPOSED MODEL

Table 3: The accepted items with their factor loadings to each factor

\begin{tabular}{|c|c|c|c|c|c|c|c|c|c|c|c|c|c|c|c|c|c|}
\hline Factor1 & $\mathrm{R} 2$ & Factor2 & $\mathrm{R} 2$ & Factor3 & $\mathrm{R} 2$ & Factor4 & $\mathbf{R} 2$ & Factor5 & $\mathrm{R} 2$ & Factor6 & $\mathrm{R} 2$ & Factor7 & $\mathbf{R} 2$ & Factor8 & $\mathbf{R} 2$ & Factor9 & $\mathrm{R} 2$ \\
\hline 31 & .462 & 36 & .425 & 32 & .559 & 1 & .434 & 66 & .767 & 78 & .748 & 24 & .489 & 14 & 0.334 & 16 & 0.501 \\
\hline 37 & .369 & 38 & .434 & 35 & .361 & 2 & .471 & 67 & .532 & 79 & .775 & 88 & .43 & 25 & 0.309 & 17 & 0.35 \\
\hline 52 & .584 & 89 & .745 & 39 & .480 & 3 & .396 & 68 & .841 & 80 & .846 & 107 & .41 & 26 & 0.335 & 18 & 0.49 \\
\hline 53 & .701 & 91 & .708 & 40 & .403 & 4 & .565 & 69 & .684 & 81 & .785 & 109 & .393 & 27 & 0.313 & 19 & 0.71 \\
\hline 54 & .792 & 92 & .806 & 42 & .506 & 5 & .607 & 70 & .755 & 82 & .765 & 110 & .644 & 28 & 0.485 & 21 & 0.801 \\
\hline 55 & .619 & 93 & .617 & 43 & .548 & 6 & .519 & 71 & .529 & 83 & .854 & 111 & .726 & 29 & 0.392 & 87 & 0.44 \\
\hline 56 & .544 & 94 & .801 & 44 & .741 & 7 & .532 & 72 & .737 & 84 & .740 & 112 & .745 & 30 & 0.452 & 103 & 0.35 \\
\hline 57 & .670 & 95 & .551 & 45 & .733 & 8 & .533 & 73 & .892 & 85 & .845 & 113 & .811 & 33 & 0.651 & & \\
\hline 58 & .624 & 97 & .414 & 46 & .455 & 9 & .407 & 74 & .483 & & & 114 & .850 & & & & \\
\hline 59 & .664 & 100 & .672 & 47 & .767 & 10 & .525 & 76 & .902 & & & 115 & .634 & & & & \\
\hline 60 & .756 & 101 & .763 & 49 & .408 & 11 & .449 & 77 & .795 & & & 116 & .625 & & & & \\
\hline 61 & .801 & 102 & .694 & 50 & .472 & 12 & .597 & & & & & & & & & & \\
\hline 62 & .716 & 106 & .609 & 51 & .517 & 15 & .406 & & & & & & & & & & \\
\hline 63 & .727 & 108 & .374 & 90 & .375 & 17 & .368 & & & & & & & & & & \\
\hline 64 & .668 & & & 98 & .617 & 20 & .49 & & & & & & & & & & \\
\hline \multirow[t]{3}{*}{65} & .595 & & & 99 & .478 & 23 & .44 & & & & & & & & & & \\
\hline & & & & 104 & .431 & & & & & & & & & & & & \\
\hline & & & & 105 & .396 & & & & & & & & & & & & \\
\hline
\end{tabular}

Table 3 shows the accepted items with their factor loadings. The factor means obtained using the sample ( $\mathrm{n}=472)$ are shown in Table 4 . The confidence interval of the means was estimated to determine its accuracy. 
Dina Samir Sayed Ali Mekky, Mohamed Atef Mohamed Mohamed El- Badramany

EXPLORATORY AND CONFIRMATORY FACTOR ANALYSIS OF PERCEIVED

SELF-EFFICACIES AMONG TEACHERS STUDENTS AT FACULTY OF EDUCATION,

HELWAN UNIVERSITY, EGYPT: FROM BANDURA'S THEORY TO PROPOSED MODEL

Table 4: Means and Standard Deviation for the Factors of perceived Self-Efficacies among teachers student (N=472)

\begin{tabular}{|c|c|c|c|c|c|}
\hline Factors & $N$ & $\mathbf{M}$ & SD. & Skewness & Kurtosis \\
\hline Planning perceived self-efficacy & 472 & 60.5508 & 10.07349 & -.505 & .366 \\
\hline Moral and emotional perceived self-efficacy & 472 & 58.9089 & 9.10858 & -1.881 & 5.033 \\
\hline Social leadership perceived self-efficacy & 472 & 66.8602 & 11.75410 & -.663 & .448 \\
\hline Academic perceived self-efficacy & 472 & 56.6568 & 8.60509 & -.321 & .604 \\
\hline Reading perceived self-efficacy & 472 & 23.7415 & 7.74932 & .034 & -.674 \\
\hline Technology perceived self-efficacy & 472 & 36.6822 & 9.79496 & -.244 & -.478 \\
\hline Research perceived self-efficacy & 472 & 40.2881 & 7.15803 & -.473 & .169 \\
\hline Motivated perceived self-efficacy & 472 & 31.6081 & 5.06025 & -.947 & 1.369 \\
\hline Creative perceived self-efficacy & 472 & 25.3581 & 4.21817 & -.286 & -.103 \\
\hline
\end{tabular}

The Cronbach's Alpha values of the nine factors were $.761, .763, .89, .86, .91, .87, .87, .83$ and .71 and the overall consistency of all items was .76. The correlation matrix using Pearson's $\mathrm{r}$ showed that the factors of perceived self-efficacies have a significant relationship over $\mathrm{p}<.05$.

Table 5: Correlation Matrix of perceived Self-Efficacies among university students

\begin{tabular}{|c|c|c|c|c|c|c|c|c|c|}
\hline Factor & (1) & $(2)$ & (3) & $(4)$ & (5) & (6) & (7) & (8) & (9) \\
\hline Planning perceived self-efficacy & ----- & & & & & & & & \\
\hline Moral and emotional perceived self-efficacy & $.602^{* *}$ & ----- & & & & & & & \\
\hline Social leadership perceived self-efficacy & $.557^{* *}$ & $.577^{* *}$ & ----- & & & & & & \\
\hline Academic perceived self-efficacy & $.611^{* *}$ & $.403^{* *}$ & $.457^{* *}$ & ----- & & & & & \\
\hline Reading perceived self-efficacy & $.301^{* *}$ & $.213^{* *}$ & $.253^{* *}$ & $.292^{* *}$ & ----- & & & & \\
\hline Technology perceived self-efficacy & $.376^{* *}$ & $.143^{* *}$ & $.268^{* *}$ & $.405^{* *}$ & $.242^{* *}$ & ----- & & & \\
\hline Research perceived self-efficacy & $.634^{* *}$ & $.560^{* *}$ & $.525^{* *}$ & $.609^{* *}$ & $.439^{* *}$ & $.373^{* *}$ & ----- & & \\
\hline Motivated perceived self-efficacy & $.697^{* *}$ & $.633^{* *}$ & $.575^{* *}$ & $.582^{* *}$ & $.304^{* *}$ & $.252^{* *}$ & $.646^{* *}$ & ----- & \\
\hline Creative perceived self-efficacy & $.549^{* *}$ & $.498^{* *}$ & $.555^{* *}$ & $.583^{* *}$ & $.261^{* *}$ & $.318^{* *}$ & $.491^{* *}$ & $.549^{* *}$ & ----- \\
\hline
\end{tabular}

${ }^{* *} \mathrm{p}<.05$ 
We start the EFA by considering all the 118 items measuring 9 aspects of perceived Self-Efficacies. The statistical criteria in this study were satisfied. The KMO value for perceived Self-Efficacies was $0.907>0.70$, which provided information about the availability of an adequate number of items for each factor.

In addition to, the value of Bartlett's Test of Sphericity [ $\chi 2=22384.218 ; p<0.001]$ was significant, rejecting the null hypothesis that the correlation matrix was an identity matrix. The following step was to identify the values of the extraction communalities, eigenvalues, percentage of variances and factor loading.

Table 6 presents the detail of factor loading, communalities, eigenvalues and percentage of variances explained by the sub-constructs of perceived Self-Efficacies. Firstly, the values of the extraction communalities represent the variance in each item calculated before and after the factor analysis. The values of such communalities for each item which were less than 0.35 were dropped from further analysis (Hidayat, Zamri and Zulnaidi, 2018). Small values $(<0.50)$ of the extraction communalities indicate that less than half of the variance in the item was considered in identifying the latent construct. In the current research, all item communalities ranged from 0.612 to 0.816 ,which exceeded the 0.50 level for adequate explanation. Next, a nine-factor solution with eigenvalues over 1 emerged from the EFA, explaining $57.03 \%$ of the variance in total. The goal factors and their contributions were as follows: Planning perceived self-efficacy,35.15\%; Moral and emotional perceived self-efficacy,4.635\%; Social leadership perceived self-efficacy, 4.374\%; Academic perceived self-efficacy, 2.908\%; Reading perceived self-efficacy, 2.421\%; Technology perceived self-efficacy, $2.144 \%$; Research perceived self-efficacy, 2.111\%; Motivated perceived self-efficacy, $1.703 \%$; and Creative perceived self-efficacy, $1.587 \%$.

\subsection{Confirmatory Factor Analysis}

Table 6: Factor loadings, communalities, eigenvalues and percentage of variances for perceived self-efficacies

\begin{tabular}{|l|l|c|c|c|}
\hline \multirow{4}{*}{$\begin{array}{l}\text { Perceived } \\
\text { Self-Efficacies }\end{array}$} & Dimensions & Eigenvalues & \% of Variance & Cumulative \% \\
\cline { 2 - 5 } & & 41.483 & 35.155 & 35.155 \\
\cline { 2 - 5 } & & 5.470 & 4.635 & 39.790 \\
\cline { 2 - 5 } & & 5.161 & 4.374 & 44.164 \\
\cline { 2 - 5 } & & 3.432 & 2.908 & 47.072 \\
\cline { 2 - 5 } & & 2.856 & 2.421 & 49.493 \\
\cline { 2 - 5 } & & 2.530 & 2.144 & 51.637 \\
\cline { 2 - 5 } & & 2.491 & 2.111 & 53.748 \\
\cline { 2 - 5 } & & 2.009 & 1.703 & 55.450 \\
\hline
\end{tabular}

In this research, the EFA suggested a nine-factor structure for the perceived self-efficacies, which were Planning perceived self-efficacy, Moral and emotional perceived selfefficacy, Social leadership perceived self-efficacy, Academic perceived self-efficacy, 
Dina Samir Sayed Ali Mekky, Mohamed Atef Mohamed Mohamed El- Badramany

EXPLORATORY AND CONFIRMATORY FACTOR ANALYSIS OF PERCEIVED

SELF-EFFICACIES AMONG TEACHERS STUDENTS AT FACULTY OF EDUCATION, HELWAN UNIVERSITY, EGYPT: FROM BANDURA'S THEORY TO PROPOSED MODEL

Reading perceived self-efficacy, Technology perceived self-efficacy, Research perceived self-efficacy, Motivated perceived self-efficacy and Creative perceived self-efficacy . CFA was conducted to verify the factorial validity of the perceived self-efficacies. CFA can support further evidence regarding the fitness of the proposed model with regard to the structure of the factors identified via EFA.

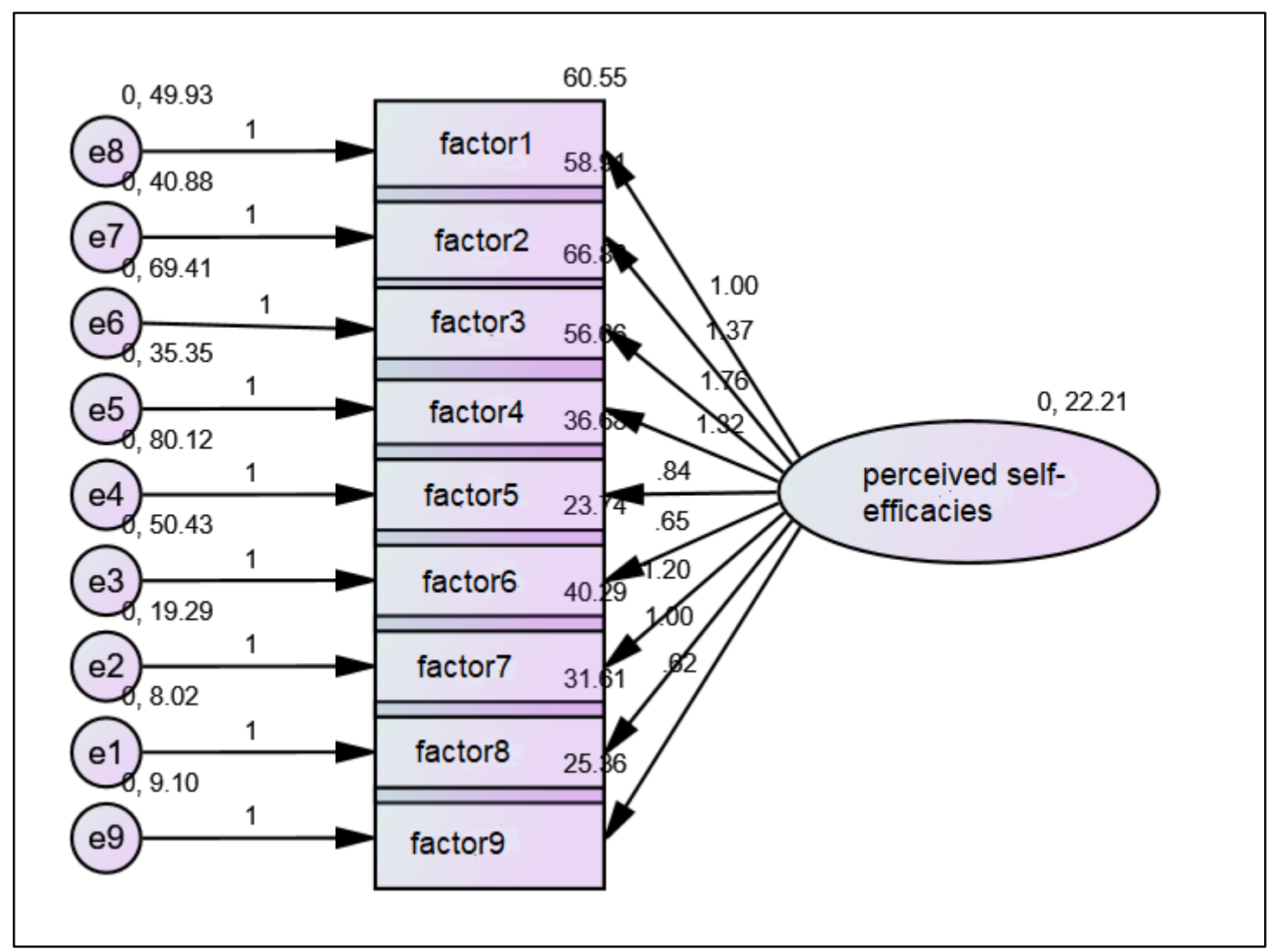

Figure 1: Confirmatory factor analysis diagram

Table 7: Model fit statistics for hypothesized factor model

\begin{tabular}{|l|c|c|c|c|c|c|c|}
\hline & $\mathbf{\chi 2}$ & $\chi \mathbf{2} / \mathbf{d f}$ & CFI & TLI & RMSEA & FMIN & ECVI \\
\hline Model & 318.919 & 11.39 & .855 & .89 & .0149 & .677 & .788 \\
\hline
\end{tabular}

The CFA is presented in route diagrams where the circles represent latent variables and the squares represent observed variables (Wong, Wong and Zhuang \& Liu, 2017). The single-headed arrows are used to imply an assumed direction of influence, and the twoheaded arrows represent the covariance between the six latent variables (Figure 1). In this analysis, the value of CMIN or Chi-square adjustment test $(\chi 2)$ of Pearson was measured, which was 318.919 with $p=0.000$, being statistically significant. However, the Chi-square value shows great sensitivity to the sample size, which is why we decided to use other adjustment indexes in order to contrast the model: the index of comparative adjustment (CFI), the Tucker-Lewis index (TLI), and the root mean square error of approximation (RMSEA) are the most relevant. 
The CFI and the TLI have a range of 0 to 1 considering these values more valid when they are closer to the unit ; in addition, the value of RMSEA is considered to indicate a good fit to the model if it is less than 0.06 (Sánchez-Oliva, Morin, Teixeira, Carraça, Palmeira and Silva, 2016). In the study, the CFI was $n=0.855$, the TLI was $n=0.89$. the RMSEA that was obtained was 0.14 , FMIN was $n=.677$ and ECVI was $n=.788$ data that show a very good fit to the hypothetical model (Murphy, Liu\& Herzog, 2019).

It is worth noting, one of the few studies that aimed to define the factorial structure of the Self-Efficacy Scale is a Firmante study (2011). His study developed an instrument that measures four factors of self-efficacy among student-athletes which were based on Bandura's sources of self-efficacy theory. The four factors are: Performance accomplishments, modelling, verbal persuasion, and emotional arousal. The survey questionnaire was validated and distributed to 157 student athletes $(\mathrm{N}=157)$. Self-efficacy is a very important aspect in dealing with different challenges in life. This would be a good instrument for counsellors who handle student. The results of the test would also help the counsellors help the student succeed in college. In addition, it can be a basis for developing programs and modules for the student. The current study differed from (Firmante, 2011) of the two researchers in terms of the nature of the sample and the dimensions of the scale used by each study.

\section{Conclusion}

The focus of this study is to determine the reliability and validity of the PSE-inventory by examining exploratory and confirmatory Factor Analysis of Perceived self-efficacies among teachers Students at faculty of education, Helwan university in the age range from 20 to 22 years old.

Based on the results of the analysis and discussion, it can be concluded that: the construct of Perceived self-efficacies had fulfilled the expected validity and reliability, and all components and indicators could significantly form Perceived self-efficacies. In this research, the Perceived self-efficacies scale measurement model was formed in accordance with empirical data obtained through the subjects at the research setting.

\section{Recommendations}

Some recommendations are suggested to strengthen research in this field: to ensure the heterogeneity of the participants, the researcher could include a greater number of participants from different academic settings. Thus, to reflect the broader population of adolescents in Egypt, the outcome of the research can be generalized. Furthermore, the methodology of the mix process in collecting the data, reliable findings can be taken into account in producing.

In addition, the recommendations of the researchers include the use of the probability sampling process, such as random sampling in the collection of data to ensure 
that the outcomes of the outcome are reflected in this study by the adolescent population. and, attention should also be paid to the creation of a psychological instrument for evaluating the perceived self-efficacies of university students in the Egyptian context. It will ensure the relevance and reliability of future research of the results on self-efficacy.

\subsection{Limitations}

In relation to the sample size, the key constraint comes from the number of participants. Future research studies should aim to extend the sample and accept the sample provided in this study as appropriate for a questionnaire to be validated.

The use of computerized PSE scale by Google form, in light of the spread of the Corona virus (COVID-19) and the application of social distancing on the other hand, gives a range of advantages over other methods of assessment. In addition to its straightforward correction and explanation, it was introduced easily and not expensively; however, it still has some drawbacks, such as the random responses that participants may perform and the challenge that some students will have to say about their own thoughts.

\subsection{Implications of the Study}

The consequences of measuring student self-efficacy are significant in terms of the nine variables that play a major role in how students interpret and how they perform in response to their respective circumstances, tasks or challenges. Rising self-efficacy generates optimistic self-perceptions, generating overall self-confidence and having a positive perspective on what is expected of them in their lives. Similarly, helping the student to excel in college and in their life. Results can be a basis for the university student in the creation of programs and modules.

\section{Conflict of Interest Statement}

The authors declare no conflicts of interests.

\section{About the Authors}

Dr. Dina Samir Sayed Ali Mekky and Dr. Mohamed Atef Mohamed Mohamed ElBadramany are a Lecturers of Educational Psychology, Faculty of Education, Helwan University. They earned their Masters and PhD of Education in Educational psychology at Helwan University. Further correspondence regarding this research paper should be addressed to the author, email: dr.dina.samir@edu.helwan.edu.eg and or dinamekky@yahoo.com.. 


\section{References}

Abd-Elmotaleb, M. \& Saha, S. K. (2013). The Role of Academic Self-Efficacy as a Mediator Variable between Perceived Academic Climate and Academic Performance. Journal of Education and Learning, 2(3),118-129.

Adeyemo, D. A. (2007). Moderating Influence of Emotional Intelligence on the Link Between Academic Self-efficacy and Achievement of University Students. Psychology and Developing Societies,19(2),199- 213.

Afsar, B., Shahjehan, A., Afridi, S., Shah, S., Bin Saeed, B. \& Hafeez, S. (2019). How moral efficacy and moral attentiveness moderate the effect of abusive supervision on moral courage?, Economic Research-Ekonomska Istraživanja, 32:1, 3437-3456.

Al-Mekhlafi, A. (2010). The effectiveness of the academic self and its relationship to certain personality traits. Damascus University Magazine, 26(2), 481-514.

Al-Rufou, M. A, al-Qaisi, T. K. \& Al-Qaraah, A. O. (2009). The relationship of self-aware competence to the ability to solve problems among students of Tafila Technical University in Jordan. Educational journal. Kuwait, 23(92), 181-214.

Al-Zaq, A. (2009). The academic self-competence of the students of the University of Jordan in light of the changing gender, faculty and academic level. Journal of Educational and Psychological Sciences, 10(2), 37-58.

Anderson, D. W., Krajewski, H. T., Goffin, R. D. \& Jackson, D. N. (2008). A leadership self-efficacy taxonomy and its relation to effective leadership. The Leadership Quarterly, 19,595-608.

Artino, A. R. (2012). Academic self-efficacy: from educational theory to instructional practice. Perspect Med Educ 1, 76-85.

Aurah, C. (2017). Investigating the Relationship between Science Self-efficacy Beliefs, Gender, and Academic Achievement, among High School Students in Kenya. Journal of Education and Practice,8(8),146-153.

Bandura, A. (1977). Self-efficacy: The exercise of control. New York: W. H. Freeman.

Bandura, A. (1995). Self-efficacy in changing societies. New York: Cambridge University.

Bandura, A. (1997). Self-efficacy: The exercise of control. New York: W. H. Freeman and Company.

Bellò, B., Mattana, V. \& Loi, M. (2018). The power of peers: A new look at the impact of creativity, social context and self-efficacy on entrepreneurial intentions. International Journal of Entrepreneurial Behavior \& Research, 24 (1) 214-233.

Bierer, S. B., Prayson, R. A. \& Dannefer, E. F. (2015). Association of research self-efficacy with medical student career interests, specialization, and scholarship: A case study. Adv Health Sci Educ Theory Pract, 20(33),9 -54.

Caprara, G. V., Barbaranelli, C., Steca, P. \& Malone, P. S. (2006). Teachers' self-efficacy beliefs as determinants of job satisfaction and students' academic achievement: A study at the school level. Journal of School Psychology, 44,473-490. 
Celik, V., \& Yesiyurt E. (2013). Attitudes to Technology, Perceived Computer SelfEfficacy and Computer Anxiety as Predictors of Computer Supported Education. Computers and Education, 60 (1), 148-158.

Chan, D. W. (2004). Perceived emotional intelligence and self-efficacy among Chinese secondary school teachers in Hong Kong. Personality and Individual Differences, 36, 1781-1795.

Çubukcu, F. (2008). A Study on the Correlation between Self Efficacy and Foreign Language Learning Anxiety. Journal of Theory and Practice in Education,4 (1),148158.

Drago, A., Rheinheimer, D. C., \& Detweiler, T. N. (2018). Effects of Locus of Control, Academic Self-Efficacy, and Tutoring on Academic Performance. Journal of College Student Retention: Research, Theory \& Practice,19(4),433-451.

Firmante, M. C. M. (2011). Exploratory and Confirmatory Factor Analysis of Self-efficacy among Student-Athletes. Educational Measurement and Evaluation Review, .2, 137-147.

Galoj, S. (2016). Leadership Self-Efficacy and Strategic Leadership Behaviour. International Journal of Social Sciences and Management Research,2(1),24-33.

Garavand, H., Kareshki, H., \& Ahanchian, M. (2014). The role of educational - Research environment and social factors on the research self-efficacy of students of Mashhad University of Medical Sciences. J Med Educ Dev, 8(32),46. 14.

Guttman, L. (1954). Some necessary conditions for common-factor analysis. Psychometrika,19, 149-161.

Haase, J., Hoff, E. V., Hanel, P. H. P., \& Innes-Ker, А. (2018). A meta-analysis of the relation between creative self-efficacy and different creativity measurements. Creativity Research Journal, 30(1), 1-16.

Hamdi, N. \& Daoud, D. (2000). The relationship of self-conscious effectiveness to depression and stress among students of the Faculty of Educational Sciences at the University of Jordan. Studies, 27(1), 44-56.

Hannah, S., \& Avolio, B. (2010). Moral Potency: Building the Capacity for character based leadership. Consulting Psychology Journal: Practice and Research, 62(4),291-310.

Hashemi, M. R. \& Ghanizadeh, A. (2011). Emotional Intelligence and Self-Efficacy: A Case of Iranian EFL University Students. International Journal of Linguistics, $3(1), 1-16$.

Hayat, A. A. \& Shateri, K. (2019). The role of academic self-efficacy in improving students' metacognitive learning strategies. Journal of Advances in Medical Education \& Professionalism, 7(4), 205-212.

Hidayat, R., Zamri, S. N. A. S., \& Zulnaidi, H. (2018). Exploratory and confirmatory factor analysis of achievement goals for Indonesian students in mathematics education programmes. Eurasia Journal of Mathematics, Science and Technology Education, $14(12), 16-48$. 
Hotelling, H. (1933). Analysis of a complex of statistical variables into principal components. Journal of Educational Psychology, 24(6), 417-441.

Hendrickson, A. E., \& White, P. O. (1964). Promax: A quick method for rotation to oblique simple structure. British Journal of Statistical Psychology, 17(1), 65-70.

Hoyt, C. (2005). The role of leadership efficacy and stereotype activation in women's identification with leadership. Journal of Leadership \& Organizational Studies, 11,2- 14.

Iyer, A., Zhang, A., Jetten, J., Hao Z. \& Cui, L. (2017). The promise of a better group future: Cognitive alternatives increase students' self-efficacy and academic performance. British Journal of Social Psychology,56,750-765.

Joo, Y. J., Bong, M., \& Choi, H. J. (2000). Self-efficacy for self-regulated learning, academic self-efficacy and Internet self-efficacy in web-based instruction. Educational Technology Research and Development, 48(2), 5-17.

Keengwe, J. (2007). Faculty integration of technology into instruction and students' perceptions of computer technology to improve student learning. Journal of Information Technology Education, 6, 169-180.

Kim, A. \& Park, Y. (2000). Hierarchical structures of self-efficacy in terms of generality levels and its relation to academic performance: General academic, domain specific and subject specific self-efficacy. New Orleans: Paper presented at the Annual Meeting of the American Educational Research Association,4,1-28.

Lashari, S. A., Shehzad, W., M., Lashari, T. A. \& Alghorbany, A. (2019). Self-efficacy sources and reading comprehension: The mediating role of reading self-efficacy beliefs.3L: Language, Linguistics, Literature, 25(3). 90-105.

Laurencelle, F. \& Scanlan, J. (2018). Graduate Students' Experiences: Developing Selfefficacy, International Journal of Nursing Education Scholarship, 15 (1), 1-10.

Lev E. L., Kolassa J., \& Bakken L. L. (2010). Faculty mentors' and students' perceptions of students' research self-efficacy. Nurse Educ Today,30, 74-169.

Linnenbrink, E. A. \& Pintrich, P. R. (2003). The role of self-efficacy beliefs in student engagement and learning in the classroom. Reading \& Writing Quarterly, 19, 119137.

Linnenbrink, E. A. \& Pintrinch, P. R. (2002). Motivation as an enabler for academic success. School Psychology Review, 31(3), 313-328.

Margolis, H. \& McCabe, P. P. (2006). Improving Self-Efficacy and Motivation: What to Do, What to Say. Intervention in School and Clinic, 41(4), 218-227.

McDonald, T., \& Siegall, M. (1992). The effects of technological self-efficacy and job focus on job performance, attitudes, and withdrawal behaviors. The Journal of Psychology: Interdisciplinary and Applied, 126(5), 465-475.

Merolla, D. M. (2017). Self-efficacy and Academic Achievement: The Role of Neighborhood Cultural Context. Sociological Perspectives,60(2), 378-393. 
Dina Samir Sayed Ali Mekky, Mohamed Atef Mohamed Mohamed El- Badramany

EXPLORATORY AND CONFIRMATORY FACTOR ANALYSIS OF PERCEIVED

SELF-EFFICACIES AMONG TEACHERS STUDENTS AT FACULTY OF EDUCATION,

HELWAN UNIVERSITY, EGYPT: FROM BANDURA'S THEORY TO PROPOSED MODEL

Merriman, L. (2012). Developing academic Self-efficacy: Strategies to support gifted elementary school students. Master thesis. School of Education and Counseling Psychology. University of California.

Mew, L., \& Honey, W. H. (2010). Effects of computer self-efficacy on the use and adoption of online social networking. IJVCSN 2, 18-34.

Murphy, K., Liu, M., \& Herzog, T. (2019). Confirmatory factor analysis and structural equation modeling of socio-cultural constructs among chamorro and nonchamorro Micronesian betel nut chewers. Ethn Health,24(6),724-735.

Penn, L. T. \& Lent, R. W. (2019). The Joint Roles of Career Decision Self-Efficacy and Personality Traits in the Prediction of Career Decidedness and Decisional Difficulty. Journal of Career Assessment. 27(3), 457-470.

Rehg, M. T., Gundlach, M. J. \& Grigorian, R. A. (2012). Examining the influence of crosscultural training on cultural intelligence and specific self-efficacy. Cross Cultural Management: An International Journal, 19(2), 215-232.

Reuter, T., Ziegelmann, J. P., Wiedemann, A. U., Geiser, C., Lippke, S., Schüz, B., \& Schwarzer, R. (2010). Changes in intentions, planning, and self-efficacy predict changes in behaviors: An application of latent true change modeling. Journal of Health Psychology, 15, 935-947.

Sánchez-Oliva, D., Morin, A. J. S., Teixeira, P. J., Carraça, E. V., Palmeira, A. L., \& Silva, M. N. (2016). A bifactor exploratory structural equation modeling representation of the structure of the Basic Psychological Needs at Work Scale. Journal of Vocational Behavior, 98, 173-187.

Satici, S. A. \& Can, G. (2016). Investigating Academic Self-efficacy of University Students in Terms of Socio-demographic Variables. Universal Journal of Educational Research, 4(8),1874-1880.

Schunk, D. H. (2012). Learning Theories: An Educational Perspective. Boston: Pearson Education, Inc.

Semadar, A., Robins, G. \& and Ferris, G. (2006). Comparing the validity of multiple social effectiveness constructs in the prediction of managerial job performance. Journal of Organizational Behavior, 27, 443-461.

Shehzad, W., M., Ahmed, R., Razzaq, S. \& Hasan, M. K. (2020). Do reading boredom and reading boredom coping strategies predict reading comprehension performance? An empirical investigation of Saudi EFL learners. Indonesian Journal of Applied Linguistics, 10(2), 445-459.

Short, S. (2014). Encyclopedia of Sport and Exercise Psychology. Thousand Oaks: SAGE Publications, Inc.

Tierney, P., \& Farmer, S. M. (2002). Creative self-efficacy: Its potential antecedents and relationship to creative performance. Academy of Management Journal, 45, 11371148.

Tiyuri A., Saberi, B., Miri, M., Shahrestanaki, E, Bayat, B. B., \& Salehiniya, H. (2018). Research self-efficacy and its relationship with academic performance in 
postgraduate students of Tehran University of Medical Sciences in 2016. J Edu Health Promot, 7,11.

Toharudin, U., Rahmat, A. \& Kurniawan, I. S. (2019). The important of self-efficacy and self-regulation in learning: How should a student be?. Journal of Physics: Conference Series, 1157, 1-7.

Voica, C., Singer, F. M. \& Stan, E. (2020). How are motivation and self-efficacy interacting in problem-solving and problem-posing?. Educ Stud Math 105, 487-517 .

Wigfield, A., Guthrie, J. T., Tonks, S., \& Perencevich, K. C. (2004). Children's motivation for reading; Domain specificity and instructional influences. The Journal of Educational Research, 97(6), 299-309.

Wong, P. K. S., Wong, D. F. K., Zhuang, X. Y. \& Liu, Y. (2017). Psychometric properties of the AIR Self-Determination Scale: the Chinese version (AIR SDS-C) for Chinese people with intellectual disabilities, J Intellect Disabil Res,61(3), 233-244. 
Creative Commons licensing terms

Authors will retain the copyright of their published articles agreeing that a Creative Commons Attribution 4.0 International License (CC BY 4.0) terms will be applied to their work. Under the terms of this license, no permission is required from the author(s) or publisher for members of the community to copy, distribute, transmit or adapt the article content, providing a proper, prominent and unambiguous attribution to the authors in a manner that makes clear that the materials are being reused under permission of a Creative Commons License. Views, opinions and conclusions expressed in this research article are views, opinions and conclusions of the author(s). Open Access Publishing Group and European Journal of Special Education Research shall not be responsible or answerable for any loss, damage or liability caused in relation to/arising out of conflict of interests, copyright violations and inappropriate or inaccurate use of any kind content related or integrated on the research work. All the published works are meeting the Open Access Publishing requirements and can be freely accessed, shared, modified, distributed and used in educational, commercial and non-commercial purposes under a Creative Commons Attribution 4.0 International License (CC BY 4.0). 